\title{
Find the best rate mortgage for you
}

Dental \& Medical Financial Services can help you to find the right mortgage product to suit your needs.

Currently, the Bank of England's (BoE) rate of interest is $0.25 \%$, the lowest for many years. It is therefore understandable why property owners are choosing a Standard Variable Rate (SVR) or Tracker mortgage, allowing more flexibility.

Typically, however, property owners that fail to plan their finances end up on their lenders' SVR. Lenders offer special rates upfront, hoping you forget to switch and pay their higher SV rates. BoE rate cuts are also, often, only passed on in part.

Tracker mortgages 'track' the BoE rate so BoE cuts are passed on in full. However, increases are too. Tracker deals on the market are now, typically, $2 \%$ above base, or higher, protecting the lender's margins. If opting for a Tracker, find one with no early redemption charges, enabling you to switch if the $\mathrm{BoE}$ rate starts to rise.
Fixed Rate mortgages still offer secured lower rates for a longer term, giving reassurance to property owners. Remember, even though the BoE base rate is low, it doesn't mean your SVR will be low. Do you know the rate you are paying for your mortgage?

Dental \& Medical Financial Services help dentists every day to find best rate mortgages suited to their personal situation. Call 01403 780770 or email info@dentalandmedical. com for more information.

\section{Prophylaxis Set-fluoridation, protection, care, sealing}

The new Prophylaxis Set from VOCO contains all the relevant products for professional dental care combined for the first time. The composition of the set means all products are close at hand at all times. In addition, the set also allows dentists and practice staff to test a number of different products and gain

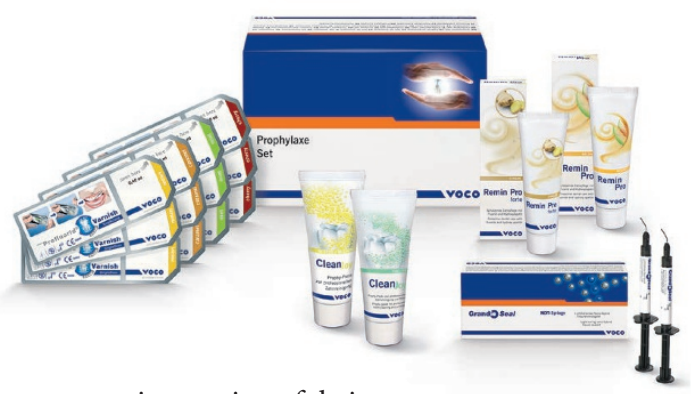

an impression of their

wide range of applications

and high level of performance. Discover

CleanJoy, the fluoride-containing cleaning and polishing paste available in two cleaning strengths with the unique traffic light coding. In addition, the set also includes the fissure sealant Grandio Seal, which has proven its worth in paediatric dentistry in particular, thanks to its excellent properties. VOCO Profluorid Varnish, the fluoride varnish for desensitisation, is included in four delicious flavours (melon, caramel, mint and cherry). The complete package is rounded off by the protective dental care product Remin Pro with fluoride and hydroxyapatite and of course Remin Pro forte with the antibacterial properties of ginger and curcuma extracts. The products can be combined to complement each other but can equally be used individually for prophylactic purposes. Each product can be reordered separately.

www.voco.com, info@voco.com

\section{Create a comfortable patient experience}

Your patients are your priority and you want them to know it. As well as exceptional dental care and a friendly, welcoming atmosphere, a dental unit from Castellini will ensure that your patients have the most comfortable experience possible.

The Skema 8 is an unrivalled example of design excellence with an infinite range of positions and synchronised movements. Patients will experience the utmost comfort as they sit back and feel the smooth pneumatic action of the backrest that automatically raises the feet as they lean back and relax.

With attractive Italian style the Skema 8 offers the perfect combination of excellent support and comfort with cutting edge technology. It is a complete treatment centre offering fully integrated specialist instruments with freedom of movement and ergonomics to enhance any treatment type. The Skema 8 has intuitive functions that can be customised to
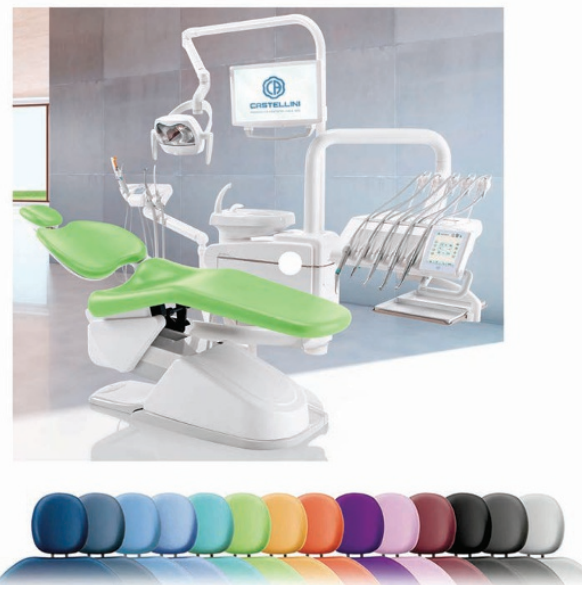

your working preferences to streamline operations and enhance your patients' confidence in your skills.

For further information call 08000933975 and speak to Castellini UK directly for assistance.

\section{Win a designer tongue cleanser this Christmas}

The Italian made AMANO tongue cleanser is designed to add elegance to the 2,000-yearold ritual of tongue scraping, which was particularly in vogue in the eighteenth and nineteenth centuries, with George Washington and Victorian aristocracy firm advocates.

Simple to use and with a range of eye-catching designs, the nickel and alloy head of the AMANO tongue cleanser is gently drawn down the tongue's surface, removing all debris in two to three strokes.

AMANO has three of its latest tongue

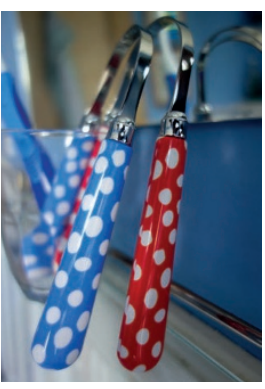

cleansers to give away to $B D J$ readers. To win, just answer the following question:

Q. Which American President is known to have used a tongue scraper?
A. George Washington
B. Bill Clinton
C. Abraham Lincoln
The first three people to email the correct answer, A, B or C, to mano@amanotonguecleanser.com, by 9 December 2016, will win an AMANO tongue cleanser.

www.amanotonguecleanser.com 